\title{
8
}
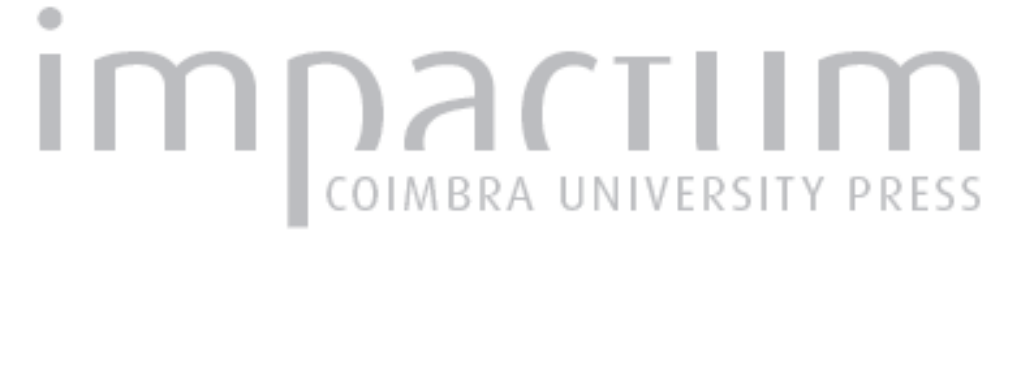

\section{[Recensão a] Vera Margarida Coimbra de Matos, Portugal e Itália. Relações Diplomáticas (1943-1974)}

\author{
Autor(es): $\quad$ Ferro, Manuel
}

Publicado por: Imprensa da Universidade de Coimbra

URL persistente:

URI:http://hdl.handle.net/10316.2/42564

DOI:

DOI:https://doi.org/10.14195/0870-8584_6_19

Accessed : $\quad$ 26-Apr-2023 15:52:12

A navegação consulta e descarregamento dos títulos inseridos nas Bibliotecas Digitais UC Digitalis, UC Pombalina e UC Impactum, pressupõem a aceitação plena e sem reservas dos Termos e Condições de Uso destas Bibliotecas Digitais, disponíveis em https://digitalis.uc.pt/pt-pt/termos.

Conforme exposto nos referidos Termos e Condições de Uso, o descarregamento de títulos de acesso restrito requer uma licença válida de autorização devendo o utilizador aceder ao(s) documento(s) a partir de um endereço de IP da instituição detentora da supramencionada licença.

Ao utilizador é apenas permitido o descarregamento para uso pessoal, pelo que o emprego do(s) título(s) descarregado(s) para outro fim, designadamente comercial, carece de autorização do respetivo autor ou editor da obra.

Na medida em que todas as obras da UC Digitalis se encontram protegidas pelo Código do Direito de Autor e Direitos Conexos e demais legislação aplicável, toda a cópia, parcial ou total, deste documento, nos casos em que é legalmente admitida, deverá conter ou fazer-se acompanhar por este aviso.

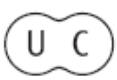




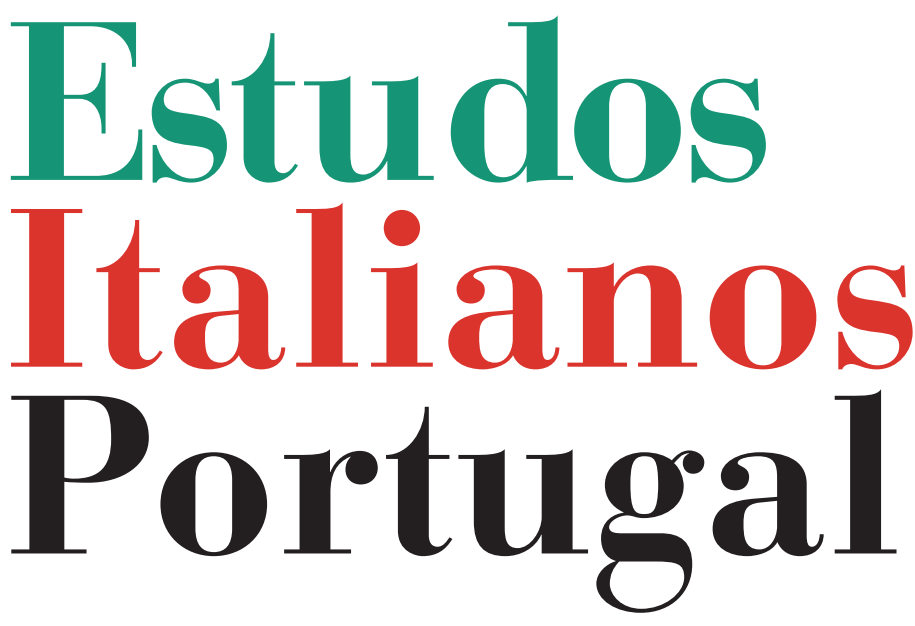

Instituto

Italiano

de Cultura

de Lisboa

Nova Série

$\mathrm{N}^{\circ} 6$ 
Così come il riconoscimento istituzionale, seppure tardivo, dell'esempio di questi antieroi ha infuso nella comunità locale una nuova coscienza civile, sradicando la rete di connivenze, di omertà ed il malaffare. Ed i risultati sono evidenti a tutti in questi ultimi tempi. Insieme all'azione di denuncia della società civile, le rivelazioni di pentiti hanno messo a nudo le implicanze politiche e la logica malavitosa dei clan.

Attraverso le confessioni di esponenti di rilievo della camorra è stata così svelata la vera natura dell'antropologia malavitosa, basata sul falso mito del guadagno imediato che ha però come conseguenze certe una morte violenta, una galera perpetua o una vita clandestina.

L'invito a "non pagare più il pizzo", rivolto dalle istituzioni e dalle organizzazioni civili ai cittadini vuol essere anche un'esortazione ai giovani a non lasciarsi irretire dall'ideologia camorristica, seppur in una condizione di estrema difficoltà dovuta a problemi cronici di disoccupazione, ribellandosi alla logica dei clan per riscattare il nome e la dignità di una comunità che non può e non deve essere identificata solo con Gomorra! UGO RUFINO
Vera Margarida Coimbra de Matos, Portugal e Itália. Relaçôes Diplomáticas (1943-1974), Coimbra, Imprensa da Universidade, 2010.

Se a bibliografia sobre o Fascismo em Itália e sobre o Estado Novo em Portugal é abundante, as relações diplomáticas estabelecidas entre os dois países e entre os dois regimes é, como a autora refere, "um tema praticamente inédito" (p. 193). Tendo em conta o período que abrange, este título abre caminho a um panorama geral das relaçōes luso-italianas dos tempos mais recentes. Insere-se numa sequência não muito vasta de estudos que abordaram esta matéria, virados embora para épocas anteriores, como a obra de Eduardo Brazão, "A unificação italiana vista pelos diplomatas portugueses 1848-1870" (Biblos, 37, 1961, e 38, 1962, Coimbra, Faculdade de Letras da Universidade), que trata do papel da diplomacia portuguesa durante o processo de unificação política da Itália; ou, a outro nível, do livro de Jorge Pais de Sousa, Uma Biblioteca Fascista em Portugal (Coimbra, Imprensa da Universidade, 2007), que apresenta a colecção de publicações 
do período fascista existentes na biblioteca do Instituto de Estudos Italianos da Faculdade de Letras de Coimbra. Todos eles compostos em ambiente académico, assumem, de resto, características bem diferentes e o mesmo se pode dizer deste livro, que é o resultado da dissertação que a autora apresentou à Faculdade de Letras, sob a orientação da Prof. ${ }^{a}$ Doutora Maria Manuela Tavares Ribeiro, em 2008, para obtenção do grau de Mestre em Estudos sobre a Europa, "As visōes do Outro".

A organização da obra segue naturalmente a perspectiva que a autora deliberou imprimir à apresentação de um panorama da história da diplomacia luso-italiana a ponto tal que o leitor se deixa conduzir pela fluência da exposição, aceitando inquestionavelmente a proposta de fazer corresponder seis capítulos aos seis períodos que identifica entre 1943 e 1974, com características muito próprias e individualizantes.

Assim, para além do "Prefácio", da responsabilidade do Professor Doutor Luís Manuel Vieira de Andrade e de uma Lista de Abreviaturas, na Introdução, procede-se à apresentação da matéria de que versa toda a obra, lançam-se os pri- meiros dados de enquadramento e esboça-se o modo como o volume se vai escandir. Alinham-se, depois, os seis capítulos referidos. O capítulo I, intitulado "Diplomacia e estratégia no período fascista”, inicia-se com uma súmula das relações entre Lisboa e o regime fascista, e apontam-se depois as afinidades ideológicas, tal como os interesses convergentes e divergentes de ambos os regimes, até à exoneração de Mussolini, muito embora considerando ainda a chamada República de Salò. O capítulo II, "O carácter simbólico de uma diplomacia de transição", subdivide-se em duas partes. A primeira trata de "A Itália e as negociaçōes da paz separada", mais centrada no desenrolar dos acontecimentos do imediato pósguerra naquele país; a segunda, "A coarctação do mussolinismo", aborda o espaço de tempo que medeia entre a assinatura da paz e a instauração da República, o governo de Pietro Badoglio e a reconfiguração da política interna e externa dos dois países. O Capítulo III, mais amplo, conta com três pontos. O primeiro deles delineia "O posicionamento euro-atlântico de Portugal e da Itália”, o segundo valoriza "Os projectos europeístas italianos e a prevista 
adesão de Portugal", enquanto o terceiro se detém sobre "As relações luso-italianas no quadro do reposicionamento euro-atlântico (1946--1950)". Aí, é tratada a fundação da NATO, a cooperação europeia de nível transatlântico, o posicionamento de Salazar, adverso à criação de instituições supranacionais, enquanto De Gasperi se mostra favorável à Federação dos Estados da Europa e se lança a ideia de uma União Latina Europeia. Por sua vez, o capítulo IV privilegia "O estreitamento dos laços históricos e de amizade" e subdivide-se também em dois pontos, de modo que o primeiro aborda "A consolidação dos vínculos históricos e políticos" entre os dois países na década de 1950 , e o segundo apresenta a situação de "A Itália e o Império Português: consenso e dissensōes". Nele, definem-se as esferas de intervenção, os interesses prioritários e a plataforma de acção comum (a NATO, em África e no Atlântico), expõem-se os motivos que conduzem à elevação das respectivas legações diplomáticas à categoria de embaixadas, assiste-se à dissidência quanto à política africana de Portugal, enquanto a Itália procura ganhar espaço de intervenção económica em Angola e Moçambique. Perante as reservas manifestadas por parte de Portugal, tem lugar o alinhamento da Itália com os movimentos anticolonialistas e o capítulo encerra-se com a apreciação da questão de Goa, bem como dos ecos que este caso alcançou na opinião pública italiana. O capítulo V, "O 'Anos de Chumbo' da diplomacia luso-italiana. A Questão Colonial", detém-se no período entre 1960 e 1967 e inclui três partes. A primeira trata de "As províncias ultramarinas: tensão e conflitualidade nas relaçóes luso-italianas", a segunda apresenta o modo como "O movimento contestatário anti-salazarista em Itália" se organiza e actua, e a terceira, numa espécie de resposta ao ponto anterior, mostra "O reforço da imagem de Portugalidade". No período aqui em causa, verifica-se, pois, um retrocesso na aproximação diplomática entre os dois países, devido à eclosão da guerra colonial. Com um governo de esquerda em Itália, tem lugar uma mobilização maciça da opinião pública contra o regime de Salazar e contra o colonialismo. Deflagram e organizam-se os movimentos estudantis de 1961-1962, gerando momentos de divergência ou convergência reservada, o que leva 
a um reequacionamento do discurso propagandístico português, assumindo-se mais convincente e objectivo. $\mathrm{O}$ último capítulo, o VI, intitulado "A consolidação das relações diplomáticas luso-italianas?", também se subdivide em dois pontos. No primeiro, "Roma e o estreitamento das relações entre Portugal e a Itália”, e no segundo, "O pragmatismo diplomático: manifestações e contrariedades", expóe-se o quadro do restabelecimento do clima de cordialidade, mediante a atitude favorável de Portugal nas votações efectuadas no âmbito das Nações Unidas, emparceirando assim, com a Itália. Em resposta, a Itália envia para Lisboa, na qualidade de embaixadores, figuras proeminentes do panorama político italiano. Apesar do retraimento ainda sentido devido ao projecto de Cabora Bassa, multiplicam-se e intensificam-se as relaçôes culturais entre os dois países. Depois, as "Conclusões" são apresentadas de modo claro e sucinto, como seria de esperar depois de uma exposição e análise detalhadas dos factos e documentos.

Todavia, para além deste interessante panorama da história diplomática luso-italiana, deve ainda referir-se a oportunidade aproveitada para a apresentação de aspectos singulares, habilmente seleccionados, para aliciar o interesse do leitor, como a curiosa apresentação da implacável imagem da Itália e dos italianos feita por Eduardo Brazão, que aparece inserida no Capítulo $\mathrm{V}$ e resulta das circunstâncias do contexto que a gerou, quando se verifica um maior atrito entre ambos os países. Outras vezes, a importância dos conteúdos extravasa o estrito âmbito da diplomacia e o discurso abre-se para outras áreas de interesse, como, por exemplo, assuntos relacionados com a História contemporânea de Portugal, não estritamente de natureza diplomática, quando se abordam aspectos relacionados com a luta socialista contra o Estado Novo e se foca a presença e a intervenção da delegação da Acção Socialista Portuguesa, composta por Mário Soares, Francisco Ramos da Costa e Manuel Tito de Morais, no XXXIX Congresso do PSI, em 1972. Na globalidade, pode ainda apontar-se a ironia com que, por vezes, os caprichos da política e da diplomacia acabam por condicionar a evolução do processo histórico. Reconhecemos, pois, que tais meandros só puderam ser 
aqui delineados graças ao grande trabalho de reelaboração dos dados recolhidos de um vasto manancial de documentos consultados.

A facilidade de leitura desta obra resulta ainda de outros factores. Para além da lista de abreviaturas, referida de entrada, a autora insere uma bibliografia selectiva onde refere a documentação consultada de acordo com as fontes, particularmente dos arquivos nacionais, dos discursos, de memórias e testemunhos pessoais, depois as fontes impressas, a imprensa, e, por fim, a bibliografia consultada. Um corpo de documentos anexos inclui um elenco de notas biográficas das personalidades citadas; uma lista de Ministros dos Negócios Estrangeiros de Portugal, entre 1943 e 1974; outra de Representantes Diplomáticos de Portugal em Roma, entre 1935 e 1974; acrescida de outras de Monarcas do Reino de Itália; Presidentes do Conselho de Ministros do Reino de Itália; Presidentes da República Italiana; Presidentes do Conselho de Ministros de Itália, do período republicano; Ministros dos Negócios Estrangeiros de Itália; e Representantes Diplomáticos de Itália em Lisboa. A fechar o volume, insere-se um conjunto de catorze textos, resultado da transcrição de documentos, que ampliam as informaçōes contidas no corpo do texto.

Se alguma restrição há a apontar a este trabalho, deve-se ao facto de a autora ter restringido a investigação para o elaborar apenas a arquivos portugueses, como, aliás, a própria reconhece, centrando-se no Arquivo Histórico Diplomático do Ministério dos Negócios Estrangeiros e no Arquivo de António de Oliveira Salazar / Arquivo Nacional da Torre do Tombo, pelo que se sente a conveniência de que um dia venha a proceder à análise crítica dos documentos produzidos pelas chancelarias italianas, depositados nos arquivos daquele país. Pelo facto, juntamos a nossa voz à do Prof. Doutor Luís Manuel Vieira de Andrade, formulando votos para que a investigação e consequente publicação dos resultados alcançados venham a ser bem sucedidos e posteriormente divulgados.

Inserido na Colecção "História Contemporânea", Portugal e Itália. Relaçôes Diplomáticas (1943-1974), de Vera de Matos, é um exemplar acabado do que é a História nos dias de hoje, pelo modo como expõe o processo interpretativo da 
cadeia dos acontecimentos que de Coimbra e, em última instânos documentos nos facilitam, ao cia, a área do conhecimento que mesmo tempo que proporciona privilegia as relações políticas, culuma profunda reflexão sobre a turais e diplomáticas entre Portuactualidade. Pelo facto, com esta gal e a Itália têm motivos de que se obra, a autora, o Centro de Estu- orgulhar.

dos Interdisciplinares do Século XX, a Imprensa da Universidade MANUEL FERRO 